\title{
Úm aspecto da nomeação de herdeiro em objeto determinado segundo o direito romano
}

\author{
Gaetano Sciascia \\ Livre docente da Universidade \\ de Roma. contratado pela Facul- \\ dade de Direito da Universidade \\ de São Paulo.
}

Perante os princípios básicos do direito hereditário romano, a nomeação de herdeiro em objeto determinado (1) constitui uma contradição nos próprios termos. Pois, o testador de um lado nomeia sucessor universal (heres) e de outro atribui-lhe coisa certa. Mesmo consistindo em conjunto único de direitos (2), a atribuição não passa de

um elemento patrimonial singular, que não se concilia com o caracter universal de herdeiro.

(1) A locução abstrata "heredis institutio ex re certa", adotada em geral para indicar nosso instituto, numca se encontra nas fontes certamente clássicas. Uma só vez, num fragmento assaz interpolado (D. $28,5,35,1$ ), acha-se "institutio ex re facta", que sem dúvida é de origem compilatória (A frase é a seguinte: " consequenter dicemus institutiones ex re factas nullius esse momenti. "!). Alhures encontra-se, segundo a forma clássica, "heres ex re institutus", "rerum heres" (D. 28, 5, 35, pr.); "heres ex re certa institutus" (Cod. Greg. 3, 4, 1) ; “certarum rerum heres" (D. 36, 1; $30)$; "certae rei heres (D. 28, 6, 41, 8).

(2) Por exemplo, de acordo com as fontes: "res Italicae" ou "res provinciales" (D. 28, 5, 35 pr.; D. 36, 1, 17, 6) ; "bona castrensia" e "cetera bona". (D. 29, 1, 11, 2; eod. 17, 1 etc.). Mesmo nestes casos soe-se designar o objeto ida instituição como "res certa". Veja-se, aliás, D. 28, 6, 41, 8 onde Papiniano relaciona a expressão "certae reí heres" com o substituto pupilar chamado a suceder na porção de herança paterna que pertence ao pupilo. 
Segundo uma partição que se tornou quasi tradicional, os intérpretes distinguem tres hipóteses de herdeiro em objeto determinado:

a) Nomeação de um único herdeiro de coisa certa;

b) Nomeação de mais herdeiros de coisa certa;

c) Nomeação de um ou mais herdeiros de coisa certa juntamente com um ou mais herdeiros regularmente instituidos.

Estudaremos em seguida o último dos tres casos que, a nosso vêr, proporciona, mais que os outros dois, os meios para tentarmos uma reconstrução histórica e dogmática do instituto. Distinguindo a regulamentação clássica (I) da justinianeia (II), ilustraremos a primeira atravês do exame crítico do texto fundamental que lhe diz respeito, indicando as fases de desenvolvimento do regime; as observações concernentes ao direito justinianeu nos darão ensejo de avaliar na sua essência as alterações sofridas pelo instituto na evolução do direito romano.

Concluindo nossas investigações, apresentaremos afinal um esboço do desenvolvimento da nomeação de herdeiro em objeto determinado, das origens até Justiniano.

1. Exegese da const. 1 Cod. Greg. 3,6 (Gordianus a. 243): observaçôes críticas quanto à autenticidade do texto.

As fontes que dizem respeito ao concurso de um ou mais herdeiros de coisa certa com um ou mais herdeiros regularmente instituidos, ainda que escassas, são muito importantes para nossa pesquisa; pois, indicam detidamente como os jurisconsultos clássicos e os compiladores bizantinos disciplinaram tal hipótese. Trata-se de um rescrito imperial do terceiro século, reproduzido no Código Gregoriano e chegado até nos, com a relativa interpretação visigótica, atravês do Breviário Alariciano. Temos, 
outrossim, uma constituição de Justiniano, o único texto do Corpus Juris que concerne à questão (3).

Lex Rom. Visig. Corp. Greg. 8,1 - De familiae herciscundae et communi dividundo.

Imp. Gordianus A. Sextio Juvenali.

Ex re certa heredem institutum sic haberi, ac si sine eius rei commemoratione heres institutus fuisset, sane officio familiae erciscundae iudicis convenire, ut non plus emolumenti consequatur, quam aliquis esset habiturus, ac si ex re certa heres institui potuisset, in dubium non venit. Falcidiam quoque in matris testamento cessare falso tibi persuasum est. Proinde, cum iuris ignorantia excusari facile non possis, si maior annis hereditati matris tuae renuntiasti, sera prece subveniri tibi desideras. P. P. XV Kal. Nov. Arriano et Papo conss. (17 de outubro de 243).

Interpretatio. Si quis per testamentum heredem aliquem appellaverit et rem certam, id est aut possessionem aut mancipia aut quamlibet aliam speciem de quo dubietas esse non possit, sub heredis vocabulo dimiserit, cui heredis nomen imposuerit, ad eum et illa quae non sunt nominata perveniant (4).

Éste rescrito é geralmente muito valorizado pelos intérpretes modernos, não apenas com relação à hipótese

(3) Não ha certeza de que a epístula de Plínio o Moço $(5,7)$ se refere ao caso. Da mesma forma, não proporcionam nenhum esclarecimento quanto ao regime nem C. $8,36,3$ pr., interpolado, nem. D. 28, 5, 35, pr., demais geral e indeterminado.

(4) Cf. Riccobono, Fontes, vol. II (2.a ed.) pág. 661. De "cum ignorantia" até o fim, i. é, na parte que não interessa nosso assunto, -o texto é reproduzido quasi integralmente em C. 1, 18, 2 com referéncia ao imperador Antonino. 
de que trata, mas também porque se alega como prova da origem clássica do recurso ao iudicium familiae ercis.cundae na nomeação de herdeiro em coisa certa. Com efeito, o texto, pela sua própria tradição independente do Corpus Juris, não pode ter sofrido interpolações bizantinas.

Entretanto Pedro Ciapessoni levantou umas dúvidas sôbre a autenticidade da constituição gordiana, indicando como glosa visigótica o trecho "sane... potuisset" (5).

$\mathrm{Na}$ verdade, a frase incriminada tem falhas estilísticas. Mas, considerada em seu conjunto, não desarmoniza do inteiro texto, pois, como veremos, concorda perfeitamente com seu conteudo. As palavras que lhe maculam a estrutura são apenas "aliquis esset habiturus ac", que, visando tornar mais claro o significado, são supérfluas.

Sòmente aí, portanto, com base em razões de forma, pode indicar-se uma glosa visigótica ou uma modificação feita pelos próprios compiladores do Breviário.

Mas não se pode suspeitar a frase apontada, considerando que a interpretação visigótica deixa de mencionar o iudicium familiae erciscundae. Não há, pois, nenhum contraste entre o rescrito e seu comentário. Explica-se neste o princlípio fundamental expresso por Gordiano no concernente à validação da institutio ex re certa. D'a própria natureza de tais "interpretationes", que o mais das vezes resumen textos clássicos (6), decorre que nem sempre se consideram nelas todos os princípios mencionados pela fonte originária. Demais disso, deve-se lembrar a maneira de formação das mesmas interpreta-

(5) P. Ciapessoni, Sul senatoconsulto Neroniano. Studi in onore di P. Bonfante, vol. III pág. 724 nota 277.

(6) Sòmente as "interpretationes" dos textos tirados das Sentenças de Paulo são mais cumpridas do trecho que comentam. Nos outros casos se trata de resumos e extratos, contendo às vezes modificações que põem em dia os mesmos textos. Cf. Patetta, Storia del diritto italiano (licções 1934), pág. 17. 
ções, derivadas, ao que parece, de precedentes elaborações escolares (7).

Mas, contra a suposição baseada no conteudo da "interpretatio" segundo a qual a frase "sane... potuisset" constitui uma tardia glosa visigótica, há uma grave objeção; pois, eliminando-se o trecho, iria faltar toda conexão entre o conteudo do texto e o título (De familiae erciscundae et communi dividundo) a que pertence. $\mathrm{E}$ visto que deveria tratar-se de glosa posterior à compilação do Breviário (ano 506), para repelir aquela objeção, seria necessário supor que as indicações dos títulos, na Lei Romana dos Visigodos, foram acrescentadas num segundo snomento, exatamente quando nosso rescrito tinha já sofrido a modificação; ou que, no caso, o próprio título foi alterado.

Ambas as hipóteses não se sustentam em face do fato de que à resposta gordiana segue-se outra constituição conexa com o mesmo título (8).

Acertado, pois, que o trecho em questão não foi acrescentado numa época posterior à da feitura do Breviário Alariciano, resta ora apurar se se trata de uma interpom lação dos próprios compiladores visigóticos, ou mesmo de unı glosa de data anterior.

Mas a primeira suposição è inverossimil, pois todos os historiadores concordam em declarar que os textos tirados do Código Gregoriano não sofreram modificaçốes

(7) O problema da origem de tais comentários é muito discutido entre os historiadores. Alguns julgam que derivem dos proprios compiladores do Breviário (Savigny, Conrat, Mommsen, Patetta); outros de uma obra das escolas orientais (Costa); a maioria dos autores pensa que os comentários foram tirados de outros comentários mais antigos, de origem ocidental.

(8) Na constituição com a "interpretatio" que segue ao rescrito de Gordiano, discute-se sôbre a validade de uma doação feita pelo pai ao filho e seus efeitos. Quanto ao problema das doações no direito romano vulgar, veja o excelente trabalho de Paulo Meréa, Estudos de direito visigótico, págs. 63-81. 
por parte dos elaboradores da Lei Romana dos Visigodos (9). Da mesma forma, não é sustentável que o trecho "sane... potuisset" foi inserto anteriormente, visto que, devendo-se assim relacionar seu conteudo com o caso de un único herdeiro em coisa certa, iria faltar a conexĩo entre a primeira e a segunda parte do rescrito, onde claramente se pressupõe contraste de interesses com outros herdeiros. Teremos, pois, oportunidade de verificar daqui a pouco que a eliminação do trecho tornaria absolulamente incomprensível o significado da constituição de Gordiano.

Cumpre nos, portanto, julgar genuino em seu conjunto o rescrito e proceder logo lhe analizar o conteudo.

2. Análise do rescrito de Gordiano. Sua conexão com o caso de nomeação de herdeiro em objeto determinado juntamente com herdeiro regularmente instituido.

O laço existente entre a primeira e a segunda parte do texto, baseado na conjunção "quoque" e no caracter adversativo do inciso "sane... potuisset", esclarece que a decisão imperial foi provocada por quem, depois de alcançada a maioridade, tinha renunciado à herança materna por motivos económicos, acreditando por erro que a lei Falcídia não se aplicasse no concernente ao testamento da mãe e que o herdeiro em coisa certa tivesse direito, como qualquer outro herdeiro, aos bens hereditários. Ignorava-se que, embora devesse considerar-se nomeado sem menção da coisa, no juizo de partilha não podia conseguir mais do que lhe pertenceria se fosse válida a instituição em objeto determinado (non plus emolumenti quam si ex re certa heres institui potuisset).

(9) Veja os autores citados na nota 7. A comparação de algumas constituições com as correspondentes do Codex de Justiniano mostra que as diferênças são, na maioria dos casos, meramente exteriores. 
Assim, deve-se pensar que Sextio Juvenal tinha sido regularmente chamado in ius, ao lado de um herdeiro instituido em coisa certa de valor insignificante; send. outrossim onerado de tal forma que não ia caber-lhe, pelı seu erro, nem a metade da herança nem a quarta Falcídia.

$\mathrm{Na}$ realidade, segundo o direito vigente, dentro dos: limites da Falcídia, o postulante tinha margem para $\mathrm{s}$. tisfazer aos legatários; e na partilha, o co-herdeiro, nomeado em objeto determinado, obtinha de fato muito menos da quota de herança que, em tese, eliminando-se a menção do objeto, lhe pertencia.

Percebendo tardiamente o erro, o interessado dirigira-se ao imperador a fim de que ele o auxiliasse, alegando que sua renuncia provinha de "ignorantia iuris". Mas. Gordiano indeferiu-lhe a petição.

Não temos dados para indicar qual foi a causa do erro do destinatário do rescrito. 0 conteudo do texto autoriza demais uma hipótese.

Séxtio Juvenal, instituido herdeiro em coisa certa, cujo: valor excedia o de sua porção abstrada de herança, tinha sido onerado gravemente com legados e nomeado juntamente com outro herdeiro chamado de modo regular. Em consequência dos mencionados erros, o interessado tinh: renunciado à herança.

Mas a frase "non plus emolumenti consequatur" deixa: pensar que o valor da porção abstrata de herança era superior ao do objeto determinado. Em todo caso, mesmo assim, não se alteram os limites da questão no ponto que nos interessa.

Por outro lado, insustentável nos parece a opinião deVicente Arangio Ruiz, segundo o qual o rescrito contem-plaria a hipótese de mais herdeiros de coisa certa (10).

(10) Cf. Arangio Ruiz, Istituzioni di diritto romano (9.a ed.) pág. 528 nota 1 . 
A suposição se concilia com a primeira parte do texto, mas não dá nenhuma explicação da segunda, que, ao invês, está em estrita conexão com a primeira. A inegável semelhança entre o inciso "sane... potursset" e a frase "sed ita, ut... consequi", contida em D. 28,5,35 pr., constitui por certo um argomento em favor da tese do ilustre autor; mas tal parelelismo, a nosso vêr, confirma apenas como na hipótese de mais herdeiros em coisa certa, assim também na de concurso de herdeiro de coisa certa com herdeiro regularmente instituido, se introduziu no último período clássico uma regulamentação baseada no officium iudicis familiae erciscundae.

Ainda menos verossimil se apresenta, porém, a hipótese de Ciapessoni, que, come se disse, elimina o trecho "sane. potuisset", riferindo o rescrito ao caso de único herdeiro de coisa certa. Tal solução torna ainda mais incerto o laço entre as duas partes do texto.

Devemos portanto julgar eliminada toda e qualquer dúvida sôbre qual o caso objeto do rescrito. Gordiano trata do concurso de um herdeiro em coisa certa junto a um herdeiro regularmente nomeado.

3. Regulamentação clássica do concurso entre herdeiros em objeto determinado e herdeiros regulares, desde que o "de cujus" dispôs do inteiro patrimonio ou de parte dele.

O rescrito de Gordiano nos atesta que, no terceiro século, segundo doutrina ja aceita totalmente (in dubium non venit), o caso de que se trata se regia da seguinte maneira.

Com base na normal ficção da detractio rei mentionis, o herdeiro ex re certa se assimilava ao herdeiro sine parte (11), assim como se dava com o herdeiro regularmente no-

(11) Isto se tira da frase “ . sic haberi, ac si sine eius rei mentione institutus fuisset", quando se tem em conta que o herdeiro de coisa certa fora instituido juntamente com herdeiro sem 
meado. No iudicium familiae erciscundae, porém, o primeiro podia obter apenas o objeto da nomeação (12), ao passo que o outro recolhia o resíduo dos bens, se houvesse (13). Com efeito, as dívidas ativas e passivas (nomina hereditária) se dividiam em igual medida entre os beneficiados; a divisão das coisas (corpora), porém, se fazia de acordo com a disposição testamentária; de forma que não havia perfeita correspondência com os quinhões abstratos de herança.

Segundo os princípios da regra ora estabelecida, o caso de mais herdeiros instituidos ex re certa ao lado de outros regularmente chamados sine parte ou em porções esgotando o monte, devia ser regido assim: cada nomeado se julgava herdeiro pelo quinhão em que era chamado ficticiamente aplicando a detractio rei mentionis e as normas gerais do concurso hereditário; no juizo de partilha, porém, os objetos determinados se atribuiam aos respectivos beneficiados e o resíduo dos "corpora" se dividia entre os outros herdeiros, de acordo com as quotas feitas pelo "de cujus" (14).

Não temos a possibilidade de estabelecer qual a regulamentação jurídica do caso em que o testador tivesse

parte. Cf. Perozzi, Istituzioni di diritto romano (2,a ed.), vol. II p. 553; Bonfante, Istituzioni di diritto romano (10.a ed.), pág. 606 . Ao mesmo recurso fazem referência D. 28, 5, 1, 4; D. eod. 9, 13; D. eod, 10; D. 36, 1, 30.

(12) Assim deve-se entender a frase "sane oficio iudicis... potuisset". Cf. os autores citados na nota precedente. Quanto às antigas interpretações, cf. Vangerow, Pandekten (1867), vol. II pág. 153.

(13) Cf. Perozzi, loco citato.

(14) Por ex., supondo A e B nomeados conjuntamente no mesmo objeto, e C e D instituidos respectivamente em 8 e 4 onças do monte: prescindindo da mentio rei e multiplicando-se o as em dupondium, A e B sucediam quantos aos "nomina" por 6 onças, C em 4 e D em 2, enquanto no juizo de partilha A e B obtinham a coisa determinada e $C_{\text {e }} \mathrm{D}$, respectivamente, $2 / 3$ e $1 / 3$ do resíduo dos "corpora". 
disposto, com instituições regulares e em coisa certa, apenas de parte de seu património; o rescrito de Gordiano, pois, formula apenas o outro caso. Pode-se supor, entretanto, que então tinha lugar a validação normal das nomeações em determinados objetos, de forma que mesm ' os "corpora" se dividiam segundo os quinhões abstratos de herança e não segundo as atribuições feitas pelo "de cujus" (15).

Destarte, o herdeiro nomeado em coisa certa não era considerado herdeiro, mas "heredis loco"; cabia-lhe a bonorum possessio, como se tivesse sido instituido sem menção do objeto; e sòmente por êste meio podia ser legitimado, quer ativa quer passivamente, a todas as ações hereditárias. A presênça de herdeiros segundo o ius civile não representava nenhum obstáculo. Nas fontes não faltam exemplos de concursos entre heredes e bonorum possessores (16). Tivemos já oportunidade de demonstrar que o bonorum possessor podia pleitear o iudicium familiae erciscundae (17).

No rescrito de Gordiano não se friza que a validação tinha lugar "iure praetorio"; pois, a decisão trata do resultado concreto da hipótese, antes do que dos meios adotados para obtê-lo.

Aliás, não é admissível que os jurisconsultos clássicos pudessem encarar o herdeiro nomeado em objeto determinado às vezes como verdadeiro heres à̀ vezes como bonorum possessor, visto que em todos os casos validavam

(15) Se, portanto, os herdeiros regulares fossem chamados em quinhões os quais em conjunto não esgotavam o monte, os hendeiros de coisa certa sucediam nos "nomina" e nos "corpora", como se chamados na parte restante do mesmo monte. No caso de a atribuição dos quinhões exceder as 12 onças, era necessário formar um dupondium e os nomeados sucediam da mesma forma na parte restante.

(16) Cf. os exemplos em Gai. 3, 41 (Ulp. 29; Inst. 3, 7, 1) e Gai. 2, 135 (Ulp. 22, 23; 28, 2; Inst. 2, 13, 3 .

(17) Cf. nosso trabalho em Archivio Giuridico, Modena 1945. 
sua instituição mediante a mesma ficção. Esta apresenta todas as características do recurso pretoriano, visando utilizar um ato ineficaz por direito estrito.

Ora, é provável que o regime do caso vertente se estabeleceu em dois diferentes momentos, exatamente correspondentes aos diferentes meios seguidos pelos juristas clássicos para obter o resultado visado. Antigamente, a jurisprudência se limitou em reconhecer o herdeiro nomeado em objeto determinado apenas como bonorum possessor, sucessor em conciarso com o heres, segundo o quinhão em que era ficticiamente chamado eliminando-se a menção do objeto; posteriormente, mais ou menos no terceiro século depois de Cristo, definindo-se a evolução do instituto, os jurisconsultos aplicaram ao caso o princípio de que o nomeado em objeto determinado praticamente conseguia a coisa certa e nada mais. Não é verossimil que a regra de Gordiano se fixasse improvisamente; pois tal ideia, como também a de que a regulamentação apareceu apenas no último período clássico, contrasta com os princípios gerais da evolução do sistema jurídico romano. Uma vez admitido o recurso da detractio rei, era natural que se lhe fizesse aplicação a toda hipótese, segundo a orientação favórável à nomeação de herdeiro (favor institutionum) que caracterizou sempre o direito hereditário romano (18).

\section{II}

1. O regime anterior a 529 e a const. 13 C. 6,24 de Justiniano.

Deve-se julgar que, no periodo pós-clássico, a regra que tiramos do rescrito de Gordiano ficou essencialmente

(18) Um ótimo testemunho, quanto ao nosso assunto, nos proporciona D. $28,2,19$, onde se exclui absolutamente a eficacia de uma deserdação ex re certa, afirmando-se: "aliam esse causam institutionis" 
inalterada. Com a aproximação entre a herança pretoriana e a civil, o herdeiro nomeado em objeto determinado foi admitido ao iudicium familiae erciscundae, podendo propor as ações hereditárias independentemente de alcancar a bonorum possessio, considerando-se, em definitivo, como herdeiro segundo o direito civil.

Em 529, a regulamentação do concurso de herdeiros: em coisa certa e de herdeiros regulares sofreu notável inovação por parte de Justiniano, em virtude de uma constituição inserta na segunda edição do Codex.

C. 6,24, 13 - De heredibus instituendis et quae personae institui non possunt.

\section{Imp. Iustinianus A. Menae pp.}

Quotiens certi quidem ex re certa scripti suni heredes vel certis rebus pro sua institutione contenti esse iussi sunt, quos legatariorum loco haberi certum est, alii vero ex certa parte vel sine parte pro veterum legum tenorem ad certam unciarum institutionem referuntur, eos tantummodo omnibus hereditariis actionibus uti vel conveniri decernimus, qui ex certa parte vel sine parte scripti fuerint, nec aliquam deminutionem earundem actionum occasione heredum ex certa re scriptorum fieri. D. VIII id. April. Constantinop. Decio vc. cons. (13 de abril de 529).

A reforma de Justiniano visava excluir das ações hereditárias, ativa e passivamente, os nomeados herdeiros em objeto determinado, que atė então, no caso deles serem nomeados juntamente com herdeiros regulares, se admiđiam à sucessão dos "nomina" segundo o quinhão em que eram chamados eliminando-se a menção da coisa certa. Das categóricas palavras do texto, resulta claramente que tal era a intenção do legislador: "eos tantummodo. . fieri". 
Mas não é da mesma forma claro o alcance da reforma justinianeia antes de mais nada, porque os termos empregados na decisão são ambïguos.

Grande dificuldade oferece, sob êste respeito, especialmente o trecho em que se colocam os herdeiros "scripti ex re certa" ao lado dos que "certis rebus pro sua institutione contenti esse iussi sunt"; i. é, os onerados de um tácito fideicomisso geral em favor dos outros co-herdeiros (19). Permanece, pois, incerta a razão de tal emparelhamento; nem se intende perfeitamente o alcance do inciso "quos legatariorum loco haberi certum est" com relação aos dois tipos de herdeiros.

Para a solução de tais questões, cumpre nos em primeiro lugar frizar a discordancia existente entre as duas partes da constituição, cuja decisão se refere, na verdade, apenas aos herdeiros em objeto determinado e não também aos outros referidos.

Nem a discordancia se justifica observando que, a respeito destes últimos, a exclusão das ações hereditárias não era uma novidade, e por isso mesmo podia obliterar-se na decisão. Pois, embora seja exato que os herdeiros a que se impos se contentassem com objetos determinados transferiam aos co-herdeiros, mediante a restituição fideicomissária (20), os onus e as vantagens, a constituição de Justiniano deixou de explicar o motivo da junção das duas figuras de herdeiros.

Ademais, não é admissível que o legislador quisesse emparelhar os herdeiros de coisa certa aos herdeiros gravados de um fideicomisso universal; pois, neste caso, a inovaçã̇o teria sido expressa com termos mais detidos e na parte da constituição em que se ditava a decisão impieríal.

(19) Sôbre tal tipo de nomeação cf. especialmente Inst. $2,23,9$; D. $32,11,4$; C. $6,36,2$; C. $5,50,11$.

(20) Cf. Gai. 2, 247 e Inst. 2, 23, 9. 
Em face de tão várias hipỏteses, cumpre nos concluir que o texto de 529, anterior à compilação do Digesto, pode-se conciliar com o regime previsto na máxima obra justinianeia, sòmente supondo que em 534, quando da inserção no Codex, o mesmo texto foi modificado pelos legisladores. bizantinos (21).

De fato, a eliminação da referência aos herdeiros gravados de um fideicomisso tácito ("vel certis... sunt"), como também a exclusão do inciso "quos legatariorum loco haberi certum est", que diz coisas inexatas mesmo por direito justamente (22), tornam o texto compreensível $\mathrm{e}$ correcto. Os acréscimos derivam necessàriamente dos Compiladores, os quais, na redação do Codex repetitae praelectionis, puseram em dia as constituições do próprio Justiniano, de acordo com as modificaçốes introduzidas nos textos clássicos e os critérios sistemáticos adotados næ elaboração do Corpus Juris.

A auto-interpolação aparecerá clara, desde que se the possam indicar os motivos.

A constituição vertente, como ato legislativo isolado, estabelece apenas que os herdeiros em objeto determinado não gozam das ações hereditárias, quando do concurso com outros herdeiros regularmente instituidos. Na conexão lógica da inteira obra legislativa de Justiniano, o texto entretanto aparece eivado de algumas alterações, onde se mencionam os herdeiros aos quais se mandou satisfazerem-se com objetos determinados "pro sua institutione". Tentamos agora explicar o significado de tais alterações.

(21) A hipótese que na segunda edição do Codex haja constituições de Justiniano interpoladas pelos próprios compiladores, já insinuada em 1889 por Otto Grandenwitz, foi desenvolvida por Emilio Albertario, Studi di diritto romano, vol V, pág. 345-35.4 com ampla bibliografia.

(22) O herdeiro nomeado em coisa certa, não concorrendo com outros herdeiros regulares, se encarou, no direito justinianeu, como "heres omnium bonorum". 
2. Explicação do acréscimo contido em C. 6,24,13 equiparando o herdeiro de objeto determinado, instituido juntamente com herdeiros regulares, ao herdeiro obrigado a restituir sua quota satisfazendo-se com determinados objetos.

A mais espontânea hipótese para explicar a interpolação há pouco apontada deveria ser aquela de que os compiladores quiseram estender a decisão imperial aos herdeiros cuja menção acrescentaram. Mas, quando se considera que tais herdeiros, desde a época clássica, transferiam fideicomissàriamente aos outros co-herdeiros tam. bém as ações hereditárias, o acréscimo se julga supérfluo e extravagante, visto que aqui está colocado fora da sedes materiae.

Pelo contrário, tendo em conta a técnica seguida pelos justinianeus modificando os textos antigos e contempora. neos segundo as exigências da obra legislativa, como também avaliando a inegável aproximação que, em consequência da reforma de 529 se determinara entre a figura do herdeiro em objeto determinado em concurso com herdeiros regularmente instituidos e a do herdeiro obrigado à restituição fideicomissária de seu quinhão, satisfazendo-se com objetos particulares, nos parece muito mais provável supor que o acréscimo tribonianeu quiz exatamente equiparar as duas espécies de herdeiros.

Não se trata de fusão de institutos jurídicos, mas apenas de igualação dos seus efeitos. A diferente natureza de cada um deles e a sua não coincidência impeden falar em processo de fusão (23).

Ora, para apreciar sob o ponto de vista juridico e legislativo a importancia da modificação, cumpre, antes de mais nada, nos referir-mos ao escopo com o qual a constituição foi originariamente baixada. No primeiro momento, por certo, Justiniano visou um fim meramente

(23) Na presente hipótese, o regime da nomeação de herdeiro em coisa certa se baseava no recurso da detractio rei mentionis, ao 
empírico: o de impedir que pudesse participar do onus das dividas ou das vantagens dos créditos quem alcançava apenas objecto determinado da herança; fato êste que devia parecer injusto à consciencia jurídica bizantina. Assim Justiniano colocou o herdeiro de coisa certa ao mesmo nivel do sucessor particular. Mas o imperador não percebeu que o herdeiro de coisa certa, despojado de todos os "nomina", i. é, dos créditos e das dívidas e, por isso mesmo, das ações, não podia dispor de algum meio para tutelar seu direito.

Na prática, portanto, a nova lei deu lugar a dificuldade; de forma que, talvéz, com base numa interpretação benigna, se reconheceu que o herdeiro nomeado em objeto determinado pudesse utilizar-se dos mesmos meios que cabiam ao herdeiro regular, pelo menos para defender seu direito e em face dos outros herdeiros. Pode ser, outrossim, que a aproximação entre o heres ex re certa e o heres instituido na maneira mencionada, com onus fideicomissário tácito, se determinou em virtude da própria praxe.

Por certo, as falhas e os inconvenientes de tal reforma não escaparam aos compiladores da segunda edição do Codex, preocupados em valorizar em máximo grau a vontade do morto, sem entretanto negar a qualidade de herdeiro ao nomeado em coisa certa.

Dai a interpolação do trecho "vel certis. . est", em virtude da qual os compiladores provavelmente visaram frizar que, na hipótese, o herdeiro em objeto determinado devia igualar-se para todos os efeitos de direito ao "heres

passo que na outra o herdeiro era tal regularmente, sendo chamado in ius. Este último obtinha a coisa certa ipso iure, ao passo que o primeiro chegava ao mesmo resultado apenas por obra do arbiter dividendae hereditatis. No direito justinianeu houve uma aproximação, no sentido de que a validação da institutio ex re certa se deu ope legis e o nomeado era excluido ipso iure das ações hereditárias. 
qui certis rebus pro sua institutione contentus esse iussus est", exatamente porque, não podendo jamais concorrer com os herdeiros regulares nos "nomina", se encontrava, como êste, "Iegatarii loco".

Os bizantinos não negaram a qualidade de herdeiro ao instituido em objeto determinado; facultando-lhe utilizar-se dos mesmos meios à disposição do herdeiro, quer para tutelar seu direito, quer nas relações com os outros co-herdeiros (24), deixaram em pẻ os efeitos da nomeação quanto à aceitação da herança, ao direito de acrescer e ao instituto da legítima (25).

3. Relações entre C. 6,24,13 e o sistema seguido pelo Compiladores na reforma da nomeação de herdeiro em objeto determinado.

Há autores que afirmam que a reforma de Justiniano se inspirou na constituição de 529, no sentido de que as modificações introduzidas nos textos das Pandectas assinalam o desenvolvimento das regras fixadas naquela lei (26). A nosso vêr, as influências da reforma não vão além do critério geral de valorizar em máximo grau a vontade do "de cujus". Sob o ponto de vista dogmático, na verdade, em face do sistema hereditário romano, a constituição instaura um ibridismo entre os princípios relativos à sucessão a título universal e a a título particular.

Mas, ao passo que Justiniano, em outras hipóteses, procedeu a uma assimilação orgánica entre herdeiro de coisa certa e prelegatário (27), no caso em apreço o im-

(24) Com efeito, para que a sucessão do nomeado se limitasse à coisa certa, era necessário qưe ele participasse do judicium familiae erciscundae.

(25) Cf. Windscheid, Pandette (trad. Fadda e Bensa), vol. III pág. 172 n.o 11.

(26) Cf. Perozzi, op. cit. vol. II. pág. 554.

(27) Cf. D. 27, 5, 79 (78) de Papiniano, onde, depois da palavra iure, foi eliminado o adjetivo praetorio. A frase final do texto é espúria. 
perador ditou uma regulamentação segundo a qual tal herdeiro não se podia encarar nem como herdeiro nem como prelegatário, mas antes como um sucessor "sui generis" participando simultaneamente da figura de sucessor a título universal e singular.

Assim, deve-se julgar que a constituição representa um caso absolutamente especial perante o regime justinianeu da instituição em objeto determinado. Como se viu, os proprios Compiladores da segunda edição do Codex, embora mantivessem firme o princípio de que os herdeiros de coisa certa, concorrendo com herdeiros regulares, eram excluidos das ações hereditárias, procuraram entretanto conciliar tal disposição com as exigências da praxe e o espírito ja seguido na compilação das Pandectas. Reconheceram assim, quanto a alguns efeitos, a qualidade de herdeiros ao nomeado, aproximando-o, quanto ao ressultado concreto, ao herdeiro a que se ordenou satisfazer-se com sua nomeaçâo.

As observações feitas nos permitem sintetizar os ressultados conseguidos, dando um panorama do desenvolvimento histórico da nomeação de herdeiro em objeto determinado, das origens até Justiniano.

$\mathrm{O}$ direito quiritário nunca reconheceu eficacia à instituição de herdeiro de coisa certa. O próprio recurso de considerar como não escrita a menção da coisa, sugerido pela jurisprudência afim de tornar a nomeação produtora de efeitos jurídicos, pressupõe o rigoroso princípio de que a nomeação de herdeiro não pode sofrer limitações de qualquer tipo.

Se for verdadeiro que a herança romana se afirmou na origem como sucessão do heres na soberania da fa- 
mília, por designação do chefe precedente (28), e que, a um certo momento, a mesma herança se transformou em sucessão nas relações jurídicas do "de cujus", é claro que não podia admitir-se sucessão de herdeiro chamado em coisa diferente do ius defuncti, pois isto era em contradição com a própria estrutura e essência da nomeação de herdeiro.

A prova de tal impossibilidade se acha não apenas no fato de que, com a evolução do ordenamento social, a exigência de dispor a título particular com objetivos puramente patrimoniais foi preenchida mediante o instituto do legado, mas também na circunstancia de que, por todo o período clássico, se manteve sempre a distinção entre aquisição universal e singular.

No fim da República e ainda mais no início do Império, a nomeação de herdeiro em coisa certa foi indiretamente reconhecida produtora de efeitos jurídicos.

Tal evolução, entretanto, se atuou de acordo com os caracteres do desenvolvimento do sistema romano, sem que as regras do direitu hereditário sofressem modificação formal. A antiga norma de ius civile, pela qual o herdeiro. não podia ser chamado a não ser no ius defuncti, aparentemente não se alterou, mantivendo-se intrega durante todo. - perıodo clássico.

O instituto inicia, portanto, sua evolução fora do sistema do ius civile; é pois o pretor que, por obra da jurisprudência, supre também neste setor às deficiencias de um ordenamento demais rigoroso e ja não correspondente às exigências sociais, reconhecendo o nomeado em coisa certa como bonorum possessor e concedendo-lhe assint ações fictícias.

(28) C.f. a revisão crítica da teoria de Bonfante feita recentemente por P. Voci, Studi in onore di V. Arangio Ruiz (1952), vol. I pág. 101-146. 
Não é verossimil que a validação se averiguasse no. ámbito do ius civile, nem mesmo por interpretação jurisprudencial, visto que, no caso, se tratava de subverter uma norma básica do mesmo ordenamento. Nem é possível que a jurisprudència se limıtasse apenas a interpretar a vontade do falecido, no sentido de que a eliminaçao da menção da coisa certa visava diretamente valorizar tal vontade. Com efeito, em virtude do caracter único da nomeação, não se podia distinguir no caso se o testadorqueria nomear herdeiro universal ou antes atribuir sòmente: um objeto do patrimonio.

Considerando que, numa espécie parecida, embora bem distinta, i. é, na de herdeiro nomeado sem que lhe caiba um determinado objeto, Gallo Aquilio estabeleceu um análogo processo de validação (29), é provável que o primeiro reconhecimento do instituto remonte ao fim da República. Aliás, a hipótese se concilia com a origem pretoriana e a natureza de simples bonorum possessor do nomeado e com a atividade que neste período a jurisprudência desenvolveu em favor das instituições de herdeiro.

Durante esta fase inicial, a atividade dos jurisconsultos clássicos se limitou à pura e simples construção do recurso à detractio rei mentionis para a validação pretoriana do instituto, determinando de caso em caso asmodalidades de aplicação segundo a variedade das si. tuaçôes concretas.

A construção, entretanto, assinala um afastamento dos. rigorosos princípios do ius civile relativos à nomeação de herdeiro.

No tardio período clássico, a nomeação em coisa certa sofre ulterior desenvolvimento destinado a modificar pro. fundamente a estrutura do instituto. É pois nesta fase que a atividade da jurisprudência se orienta no sentido.

(29) Cf. D. 28, 5, 75 e o trabalho nos Anais da Pontifícia Universidade Católica de S. Paulo, 1947-1948, pág. 225 sobre a nomeação de herdeiro com exclusão de um objeto determinado. 
de interpretar, antes de mais nada, a vontade do tes. tador.

Acontece, portanto, que nos casos em que tal vontade apresenta elementos que não deixam dúvidas sôbre as intenções do testador, os jurisconsultos sugerem novo recurso baseado no sistema acolhido anteriormente. $O$ testamento, pois, se valida sempre mediante a costumeira ficção pretoriana, de forma que, havendo mais herdeiros instituidos, cada um alcança a bonorum possessio segundo - quinhão a que é ficticiamente chamado, prescindindo-se da menção da coisa certa; porém, no caso de o testador ter esgotado todo seu patrimonio com as instituições, ou também quando as disposições dizem respeito a conjuntos patrimoniais economicamente distintos, no juizo de partilha o árbitro atribui as coisas determinadas aos respectivos beneficiados e, mediante cauções recíprocas entre os mesmos, torna possível a cada um deles participar dos "nomina" apenas segundo a correspondência deles com cada objeto atribuido.

Semelhante solução se adota no caso de concurso entre herdeiros regulares e herdeiros em coisas certas (30); ao passo que, em todas as outras hipóteses, dá-se a pura e simples validação pretoriana, não sendo possível estabelecer exatamente a efetiva vontade do "de cujus" (31).

Reafirma-se de tal maneira o favor institutionum: mas o antigo regime se aperfeiçoa, concretizando-se em determinados elementos objetivos de interpretação da vontade.

Grande é analogia que há com o testamento do soldado, no tocante do qual vige a norma de que um dos herdeiros nomeados sucede, quanto aos "corpora", apenas nas coisas que lhe foram atribuidas, participando, quanto aos "nomina", como herdeiro sine parte (32).

(30) Cf. D. 28, 5, 79; D. eod. 35.

(31) Cf. por ex. D. 28, 5, 11 Javol., que refere a opinião de Próculo. 
A orientação é geral, movendo-se no sentido de derrogar os princípios clássicos da successio in ius defuncti.

A constituição de Gordiano, reportada acima, na qual se reafirmam os princípios clássicos, foi acolhida numa compilação de leis do IV século, o Códex Gregorianus, e posteriormente na Lei Romana dos Visigodos.

Visto que naquele rescrito se contêm regras absolutamente clássicas, podemos afirmar que no período romano-helênico o instituto da nomeação de herdeiro em coisa certa seguiu em geral a evolução do sistema jurídico romano. A constante assimilação entre direito civil e o pretoriano e, por isso mesmo, a gradual aproximação entre herança e bonorum possessio provalvemente originou, por obra da praxe, o uso de conferir legitimação ao herdeiro de coisa certa às ações hereditárias, independentemente de alcançar a bonorum possessio. De forma que podendo tal herdeiro acionar e ser acionado com a petitio hereditatis, como também participar do juizo de partilha entre co-herdeiros, se determinou a igualação entre heres ex re e heres civil.

Por outro lado, desaparecida qualquer distinção entre officium iudicis e officium praetoris, como consequencia da simplificação das formas processuais, se acentuou a aproximação entre herdeiro de coisa certa e herdeiro-legatário, determinando no direito justinianeu a efetiva fusão das duas figuras.

Com Justiniano se perfaz afinal a evolução do instituto. As fictiones pretorianas, pois, decorrem diretamente da lei e a repartição dos "corpora" segundo a vontade do testador não depende do poder discricionário do iudex familiae erciscundae, mas de uma norma que obriga o proprio juiz.

Este desenvolvimento apresenta entretanto um desvio especial; pois, em 529, antes da Compilação das Pandectas,

(32) Veja o que escrevemos em Seminar, V, (Washington 1947), pág. 31-38. 
uma constituição de Justiniano dispõe, em contraste com o direito até então vigente, que os nomeados em objeto determinado ficam excluidos das ações hereditárias, quando. concorrem com herdeiros regulares.

Mas tal reforma não altera o regime geral do instituto, ditado na Compilação justinianeia; opera apenas uma mescla dos princípios relativos à sucessão a título universał e a título singular.

O ibridismo pode-se explicar como uma des consequencias da evolução pós-clássica das relações entre testamento e codicilo; mas a referencia ao instituto do fideicomisso, feita pela constituição de 529 , não autoriza a considerar a nomeação em objeto determinado como especial fideicomisso, visto que aquela referencia não passa de uma tentativa de determinar a situação íbrida do herdeiro de coisa certa em concurso com herdeiros regulares (33).

(33) O problema da distinção entre sucessor universal e singular mereceria uma profunda análise no direito brasileiro, em que - herdeiro, ipso iure, não responde além das forças da herança (art. 1587 Cód. Civ.). Os autores, em geral, se limitam a reproduzir sôbre o ponto observações de interpretes de direito estrangeiro (cf. entre eles de recente G. Stolfi, Riv. trim. Dir. e Prov. civ, 1949, 3) sem perceber que a responsabilidade limitada do herdeiro vai alterar o próprio conceito de herança, tirando-lhe os últimos vestígios de sua noção romanística, ainda existentes nos ordenamentos da Europa continental e da América latina, com exclusão do México. Nesteponto o legislador brasileiro deu um passo natural, sob o aspecto prático e evolutivo, mas revolucionario quanto ̀̀ tradição e a doutrina. Estudo análogo no sistema romano, é o do direito do patrono aos bens do Latino Juniano falecido, que cabem como se constituissem peculio, i. é, com responsabilidade limitada. A legitima expectiva do patrono, quanto aos bens que deixará seu Latino Jumiano, pode ser objecto de actos juridicos, com conteudo aleatório (cf. Gai. 2,$195 ; 3,58 ; 2,155$ ), sem que haja violação do princípio de que não se dá herança de pessoa viva (hereditas viventis non datur, cf. art. 1.089 Cód. Civ.). Atualizando o direito romano, poderiamos encarar as capacidades produtoras do Latino Juniano como uma espécie de "aviamento", de valor pecuniário. 